\title{
Pre-collisional Crustal Structure Adjacent the Indus-Yalu Suture
}

\author{
T Mark Harrison ${ }^{1 *}$, Donald J Depaolo² and Amos B Aikman ${ }^{3}$ \\ 1 Institute of Geophysics and Planetary Physics, UCLA, Los Angeles, CA 90095, USA \\ 2 Earth and Space Science $\mathcal{E}$ LBL, University of California, Berkeley, CA 94720, USA \\ ${ }^{3}$ Research School of Earth Sciences, Australian National University, Canberra, ACT 0200, AUSTRALIA \\ * For correspondence, email: director@igpp.ucla.edu
}

Understanding the evolution of the Indus-Yalu Suture (IYS) has significance well beyond its key role in recording events of the Indo-Asian collision. Although this continent-continent collision is likely just reaching middle age, the IYS is already largely bereft of ophiolitic rocks and the adjacent subduction complex is completely absent. This serves as a powerful cautionary example to those who see the apparent absence of ophiolites in Archean terranes as counterevidence of plate tectonics. Knowledge of the pre-collisional geometries of India and Asia is vital to assessing when collision began and how much convergence was accommodated by thickening, extrusion, or delamination. However, post-collisional thrusting and strike-slip faulting have transmogrified the suture zone to such an extent that little can be learned about syn-collisional crustal structure from its direct study. In light of these limitations, we have investigated rocks adjacent the IYS isotopically with a view to inferring crustal thickness through time. $\mathrm{Nd}$ isotopic data from K-T granitoids in a $\mathrm{N}-\mathrm{S}$ traverse near Lhasa show a pronounced gradient in $\mathrm{eNd}$, with mantle-like values adjacent to the IYS $(+5)$ and $\varepsilon_{\mathrm{Nd}} \approx-12$ at $\sim 120$ $\mathrm{km}$ north of the suture. This type of spatial gradient in $\mathrm{eNd}$ is interpreted as reflecting decreasing mantle input/increasing crustal assimilation due to progressively thickened crust (i.e., higher lower crustal temperatures enhance crustal assimilation). Using a calibrated crustal thermal model, we can then relate $\varepsilon_{\mathrm{Nd}}$ to crustal thickness. A test of this model may be possible using the recently calibrated zircon thermometer as crystallization temperature spectra and inheritance patterns are characteristic of specific assimilation scenarios. Our preliminary results suggest that the strong continentward gradient in assimilation is due to a gradually decreasing mantle magma flux and increasing crustal thickness; from $\leq 20 \mathrm{~km}$ adjacent the IYS to $\geq 50 \mathrm{~km}$ in the northern portion of the Gangdese Batholith where the granitoids are essentially $100 \%$ crustal melts. South of the suture, emplacement of the $44 \pm 1 \mathrm{Ma}$ Dala granites into highly deformed Tethyan Himalaya units indicates that significant crustal thickening had occurred there prior to 'hard collision'. However, no current model for evolution of the IYS yet explains why such magmas should appear south of the suture. The similarity of $\varepsilon_{\mathrm{Nd}}$ in the Dala granites and Lhasa terrane crustal melts is consistent with lower crustal flow southward across the IYS, but more likely reflects the origin of the Lhasa terrane and Tethyan Himalaya as adjacent blocks in the northern Gondwana Supercontinent. 